\title{
Intoxication before last sexual intercourse and HIV risk behavior among men and women in Uganda: Evidence from a nationwide survey
}

\author{
Nazarius Mbona Tumwesigye', Rhoda K. Wanyenze ${ }^{2}$, Tom K. Greenfield ${ }^{3}$ \\ 1 Department of Epidemiology and Biostatistics, School of Public Health, Makerere University College of Health Sciences, Uganda \\ 2 Department of Disease Control and Environmental Health, School of Public Health, Makerere University College of Health \\ Sciences, Uganda \\ 3 Alcohol Research Group, Public Health Institute, U.S.A.
}

\section{ABSTRACT}

Aims: To establish the prevalence of intoxication before sex and its association with risky sexual behavior.

Design: The data were from the 2006 Uganda Demographic and Health Survey which had been designed for a cross-sectional descriptive study.

Setting: The study covered the whole of Uganda.

Participants: The respondents were 6,253 women and 1,804 men who had ever had sex.

Measurements: The key independent variable was intoxication before last sexual intercourse, while the major outcome variables were condom use and sex with non-regular partners. Weighted prevalence of intoxication was computed and multivariate logistic regression was applied to assess the independent association of intoxication with risky sexual behavior.

Findings: Twelve percent of men and $16 \%$ of women reported having been intoxicated before last sexual intercourse. Of the women who reported that one of the partners was intoxicated before last sexual intercourse, $78 \%$ said it was their partner who was intoxicated. Of the men who reported intoxication, $83 \%$ said it was they themselves who were intoxicated. Intoxication of men was associated with having sex with non-regular partners $(O R=$ 1.78, 95\% Cl: 1.04-3.03) and having unprotected sex $(\mathrm{OR}=1.71,95 \% \mathrm{Cl}: 1.07-2.73)$. Women who were intoxicated were less likely to have been with non-regular partners $(\mathrm{OR}=0.55,95 \% \mathrm{Cl}$ : $0.32-0.95)$. The women whose partners were intoxicated were more likely to report having had unprotected sex $(\mathrm{OR}=1.55,95 \% \mathrm{Cl}: 1.12-2.15)$.

Conclusions: HIV prevention mechanisms should address intoxication before sex. More effort is needed to find ways of helping women avoid unprotected sex with intoxicated partners.

Correspondence: Nazarius Mbona Tumwesigye, School of Public Health, Makerere University College of Health Sciences, New Mulago Hospital Complex, Mulago Hill, Kampala, Uganda.

Phone: +256 782-44-777I

E-mail: naz@musph.ac.ug

Financial support: The data for this paper were derived from the 2006 Uganda Demographic and Health Survey (UDHS) dataset, which is given out freely by Uganda Bureau of Statistics and ORC Macro of Calverton, MD, U.S.A. No funding was received to produce this paper. Declaration of interests: There were no competing interests.

Acknowledgment: The data for this study were derived from the 2006 UDHS dataset. This work was presented in the Kampala KBS thematic meeting on November I5, 20I0, which was funded by FORUT, World Health Organization, GENACIS and IOGT. 
Engaging in sexual behaviors under the influence of alcohol can impair judgment, compromise power relations and increase the likelihood of risky sexual behavior (Uganda Bureau of Statistics [UBOS] \& Macro International, Inc., 2007). The situation is made worse with intoxication, since in this state self-control and executive functions are impeded. Intoxication is a major aspect of harmful use of alcohol, which is defined as a pattern of alcohol use that causes damage to health and often includes adverse social consequences (World Health Organization [WHO], 20IIa). According to the World Health Organization (WHO), harmful use of alcohol has serious effects on public health and is considered to be one of the main risk factors for poor health globally (WHO, 20I0). Harmful use of alcohol is also a major risk factor for HIV and other sexually transmitted infections, and research investigating this and other risk factors is a public health priority (Cook \& Clark, 2005; Woolf-King \& Maisto, 20II). The U.S. National Institute on Alcohol Abuse and Alcoholism (NIAAA) acknowledges the importance of considering alcohol misuse in developing comprehensive HIV prevention strategies (Bryant, 2006).

A survey conducted in the United Kingdom found intoxication before sexual activity to be more prevalent among young individuals than older people: among individuals born between I980 and I984, 6.4\% were intoxicated at first sexual encounter compared to $2.5 \%$ of those born between I946 and I949 (Aicken, Nardone, \& Mercer, 20I0). A study in Bulawayo, Zimbabwe, found that half of sex workers interviewed said their clients were intoxicated during the most recent sexual encounter (Wilson, Sibanda, Mboyi, Msimanga, $\&$ Dube, I990). In Tuvalu, a study of young people aged $15-24$ found that $19 \%$ of men and I\% of women had sex while intoxicated in the previous 12 months (Tuvalu Central Statistics Division \& Macro International Inc., 2007).

Many studies have identified a strong relationship between alcohol consumption and risky sexual behavior. A study carried out among HIV-positive women in the United States found a strong association between alcohol use and non-use of condoms (Clark, Kissinger, Bedimo, Dunn, \& Albertin, I997), while a study in Spain found a strong relationship between alcohol consumption and risky behavior for HIV (Castilla, Barrio, Belza, \& Fuente, I999). Kalichman and colleagues reviewed 33 studies of alcohol use and risky sexual behavior in sub-Saharan Africa, and concluded that any alcohol use, and especially consumption of high quantities, was significantly associated with risky sexual behavior and risk of HIV infection (Kalichman, Simbayi, Kaufman, \& Cain, 2007). A study among people involved in national service in Nigeria found a strong association between intoxication and risky sexual behavior (Sunmola, Olley, \& Oso, 2007), and a study in the United Kingdom reported a significantly higher proportion that had sex with non-regular partners among those who drank alcohol compared to those who did not drink alcohol. A review of the above studies and others shows that most studies on alcohol use and risky sexual behavior are based on small samples, focus on special groups, and use general alcohol use and risky behavior measures. In addition, such studies are generally fewer in developing countries.

A recent review of studies on alcohol and risky sexual behavior categorizes them in three groups: global association, situational overlap and event level studies (Woolf-King \& Maisto, 20II). The global association studies assume that an individual who engages in a risky sexual behavior is likely to engage in another (Cooper, 2002). These studies show that heavy alcohol consumption is associated with increased likelihood of multiple or casual sexual partners and unprotected sex (Woolf-King \& Maisto, 20II). Situation overlap studies focus on the idea that an individual who consumes alcohol in a specific situation is more likely to engage in risky behavior in that situation. These studies show that men's alcohol consumption and that of their partners results in increased likelihood of unprotected sex, while for women only their partner's consumption of alcohol was associated with the same risk (Kalichman, Simbayi, Cain, \& Jooste, 2007; Kalichman, Simbayi, Jooste, \& Cain, 2007). Event level studies carry out an in-depth examination of a specific behavior occurring on a specific occasion, and are considered more precise than global association and situational analysis studies (Weinhardt \& Carey, 2000; Woolf-King \& Maisto, 20II). However, few event level studies have been conducted in sub-Saharan Africa (Woolf-King \& Maisto, 20II). Key findings from event level studies show that alcohol use was significantly associated with unprotected sex and that the odds of engaging in unprotected sex were highest when male partner had been drinking (Kiene et al., 2008).

Heavy drinking or intoxication and HIV-risky sexual behaviour studies have shown similar association as those of general alcohol use and risky behavior. A U.S. study found that frequency of alcohol use was correlated with the number of sex partners reported by respondents $(\mathrm{p}=.003)$, while another study reported that the quantity of alcohol consumption was correlated 
with two indicators of risky sexual behavior: having multiple sexual partners ( $<<$. .oo I) and having sexual intercourse without a condom (p < o.ooI) (Gerbi, Habtermariam, Tameru, \& Nganwa, 2009). A recent study in the state of Goa, India, found that after controlling for four demographic factors, volume of consumption and, in separate models, frequency of heavy drinking predicted risky sexual behavior. Stronger associations were seen for a measure capturing heavy drinking occasions than for a measure reflecting usual quantity and frequency of consumption (Greenfield et al., 2010). This again suggests that drinking pattern measures are likely to show stronger associations with risky sexual behavior than simple volume measures. However, a few studies have offered contradictory evidence: for example, one U.S. study found that while alcohol use was correlated with increased sexual activity, intoxication was not (Bisakha, 2002).

Few nationwide studies have been undertaken to establish the relationship between intoxication or alcohol use and risky sexual behavior. A national study of adolescents in Finland found that engagement in sexual activity increased with frequency of alcohol use. Frequent intoxication-related drinking increased the probability that the teenagers had experienced sexual intercourse and had had unprotected sex. Further, the likelihood of engaging in unprotected sex and/or having multiple sexual partners increased significantly with reports of intoxication (Lavikainen, Lintonen, \& Kosunen, 2009).

Worldwide there is still little research work done on intoxication prior to sexual activity, and the paucity of such work is more evident in sub-Saharan Africa. Most of the few studies conducted on intoxication before sex have been in well-defined social settings only (Kongnyuy \& Wiysonge, 2007). While there has been evidence of association between alcohol consumption and risky sexual behavior in Uganda, the data were from localized sample surveys and were limited to alcohol consumption rather than hazardous drinking patterns including intoxication. Much less is known about the relationship between intoxication before sexual activity and risky sexual behavior. A study in Rakai, Uganda, found that $75 \%$ of participants in a population cohort study from 2006 to 2008 reported alcohol use before sex, and alcohol use by either partner before sex was found to be associated with twice the risk of HIV transmission than no alcohol consumption (Zablotska et al., 2006)

Uganda combines a high HIV sero-prevalence and a high level of alcohol consumption (WHO, 2004). In 2004 Uganda had the highest per capita alcohol consumption in the world, with an average of I9.4 li- ters of pure alcohol per capita (WHO, 2004). Despite a decline by 20II, Uganda still had the second highest per capita alcohol consumption in Africa (II.93 liters) and the 28th highest in the world (WHO, 20Irb). Given such evidence, it is hypothesized that alcohol consumption may complicate and even undermine HIV prevention efforts. This paper investigates the prevalence of intoxication during sexual activity and associated risky behavior in a nationwide sample. The risky behaviors examined in relation to this association are having multiple sexual partners and non-use of condoms.

\section{Method}

The data were extracted from the Uganda Demographic and Health Survey (UDHS) conducted in 2006, which had $8,53 \mathrm{I}$ female and 2,503 male respondents. The overall response rate of the survey was $98 \%$ (UBOS \& Macro International Inc., 2006). The sample for the survey was drawn using a two-stage cluster sampling; in the first stage 368 clusters were randomly selected and in the second stage 25 to 30 households were randomly selected from each of the clusters. The data collection was through face-to-face interviews. The primary sampling units (PSU) for the survey were clusters selected from the 2002 national census while the secondary sampling units (SSU) were households in the clusters. All women aged I5 to 49 and men aged I5 to 54 who were either permanent residents of or visitors to the households were eligible for the interview. More details on the methods of the survey can be found in the UDHS report (UBOS \& Macro International Inc., 2006).

Of the men and women surveyed in the UDHS, 7,243 women and 2,068 men had ever had sex, but only 6,206 women and I,8Io men had had sex in the previous 12 months and responded to questions on alcohol use. The final weighted sample had 6,253 women and I,804 men. Respondents were asked two questions about intoxication before last sexual intercourse: whether the respondent was intoxicated the last time he or she had sex, and whether the respondent or his/her partner was intoxicated the last he or she had sex. Intoxication was measured based on respondents' perception and recollection of their partner's and their own intoxication.

The data extracted from the UDHS data for the analysis included background characteristics and the variables on drinking before last sex, and several outcome measures. The background characteristics examined were geographical region, education level, marital status, type of residence, religion, occupation and age 
group. The key outcomes of interest were condom use during last sexual intercourse and having sexual intercourse with a non-regular partner during the same event. The key independent variable was intoxication before last sexual intercourse.

The first stage in the analysis involved computing the weighted prevalence of intoxication before last sexual intercourse by background characteristics. The second level of analysis established the association of intoxication with risky sexual behavior on bivariate analysis. Finally, we established the independent influence of alcohol consumption on risky behavior using multi-variable logistic regression analysis to control for other risk factors. For different outcomes various covariates were adjusted to achieve the best model fit. Hosmer-Lemeshow's goodness-of-fit test was used due to the large number of observations and the relatively high number of covariate patterns (Hosmer \& Lemeshow, I989; Erdural, 2006). P-values higher than .05 are regarded as acceptable for a good fit of the model, since they show minimal difference between the fitted and observed probability of occurrence of the outcomes of interest (Erdural, 2006), which in this study are condom use and sex with non-regular partners.

\section{Results}

\section{Sample characteristics}

Of the I,804 men selected for this study, 59\% $(N=1,065)$ were under 35 years old. Six percent $(N=$ Io9) did not have any formal education and $78 \%$ ( $N=4$ I5) were married. The sample of the men was drawn from all four regions of the country andKampala, the capital city, in proportion to the respective population sizes, with the highest proportion $(29 \%$, $N=520$ ) from western region and the lowest from Kampala (9\%, $N=$ I54). Fifty-eight percent of the men $(N=\mathrm{I}, 037)$ were self-employed in agriculture.

Like the men, most of the 6,253 women selected for this study were of young or middle age, with $72 \%$ $(N=4,502)$ below 35 years. Slightly over one-fifth of the women $(N=\mathrm{I}, 329)$ had had no formal education, and most $(82 \%, N=5, \mathrm{I} 29)$ were married. The women were selected from all four regions of the country and Kam- pala in proportion to population size, with the highest number from the western region $(27 \%, N=1,715)$ and the lowest number from Kampala $(8 \%, N=490)$. More than two-thirds $(69 \%, N=4, \mathrm{IO} 4)$ of the women were self-employed in agriculture.

\section{Level of intoxication before sex}

Nineteen percent $(N=339)$ of the men and $24 \%$ $(N=\mathrm{I}, 488)$ of the women reported that they themselves or their partners had used alcohol before last sexual intercourse. Twelve percent $(N=216)$ of the men and I6\% ( $N=$ I,OI4) of the women said they or their partners were intoxicated before last sexual intercourse. The proportion that simply reported alcohol consumption without intoxication was low $(6.7 \%$ of men and $7.6 \%$ of women) (Table I, Table 2 and Figure I). Of the men who reported intoxication before last sexual intercourse, $78 \%$ ( $9.4 \%$ of the total sample) said it was they alone who were intoxicated, while $83 \%$ (13.5\% of the total sample) of the women who reported intoxication said it was their partners who were intoxicated (Figure 2). Few respondents reported that both were intoxicated before last sexual intercourse (1.7\% of men and $2.2 \%$ of women).

The level of intoxication before last sexual intercourse varied by region, education level, marital status, religion and age group of the respondents. Among men, the highest level of intoxication before last sexual intercourse was reported in the northern region (15\%), among those who were uneducated (I9\%), who were widowers or separated (22\%), residents of rural areas (I2\%), Catholics (I7\%) and those aged 45 to 54 years (21\%). Among the women, the highest level of intoxication before last sexual intercourse was reported in the northern region (26\%), among those who were uneducated $(24 \%)$, who were widowed or separated (21\%), Catholics (20\%), those employed in unskilled labour $(2 \mathrm{r} \%)$ and those aged 35 to $44(23 \%)$. Overall, the lowest levels of intoxication before last sexual intercourse were reported in the central region, among those with higher levels of education, single people, urban residents, Muslims, those engaged in manual labour, and the youngest age group. 
Table 1

Weighted prevalence of reported intoxication during previous sexual activity by background characteristics of men

\begin{tabular}{|c|c|c|c|c|c|}
\hline Characteristics & $\begin{array}{l}\text { Respondent } \\
\text { alone } \\
\text { intoxicated } \\
(\%)\end{array}$ & $\begin{array}{c}\text { Partner alone } \\
\text { intoxicated } \\
\text { (\%) }\end{array}$ & $\begin{array}{c}\text { Both } \\
\text { intoxicated } \\
(\%)\end{array}$ & $\begin{array}{c}\text { Any } \\
\text { intoxicated } \\
(\%)\end{array}$ & $\begin{array}{c}\text { Total } \\
\text { respondents } \\
\text { (N) }\end{array}$ \\
\hline \multicolumn{6}{|l|}{ Region } \\
\hline Central & 5.6 & 0.8 & 0.9 & 7.2 & 368 \\
\hline Kampala & 4.5 & 2.5 & 2.8 & 9.8 & 154 \\
\hline Eastern & 10.2 & 1.0 & 1.9 & 13.4 & 421 \\
\hline Northern & 11.3 & 1.1 & 2.5 & 14.9 & 342 \\
\hline Western & 11.5 & 0.2 & 1.4 & 13.1 & 520 \\
\hline \multicolumn{6}{|l|}{ Education } \\
\hline None & 13.5 & 1.8 & 3.5 & 18.7 & 109 \\
\hline Primary & 10.4 & 0.8 & 2.1 & 13.2 & 1,184 \\
\hline Secondary & 5.3 & 0.6 & 0.5 & 6.4 & 382 \\
\hline Higher & 9.3 & 1.6 & 0.5 & 11.4 & 130 \\
\hline \multicolumn{6}{|l|}{ Marital Status } \\
\hline Single & 2.6 & 0.3 & 1.5 & 4.4 & 292 \\
\hline Married & 10.4 & 0.8 & 1.6 & 12.9 & 1,415 \\
\hline Widowed/separated & 14.7 & 3.9 & 3.6 & 22.2 & 97 \\
\hline \multicolumn{6}{|l|}{ Residence } \\
\hline Urban & 6.9 & 2.1 & 1.8 & 10.8 & 282 \\
\hline Rural & 9.9 & 0.7 & 1.7 & 12.2 & 1,521 \\
\hline \multicolumn{6}{|l|}{ Religion } \\
\hline Catholic & 13.0 & 1.5 & 2.5 & 17.0 & 776 \\
\hline Protestant & 9.5 & 0.4 & 1.6 & 11.4 & 684 \\
\hline Muslim & 1.4 & 0.7 & 0.0 & 2.1 & 202 \\
\hline Other & 0.8 & 0.0 & 0.7 & 1.5 & 143 \\
\hline \multicolumn{6}{|l|}{ Occupation } \\
\hline Professional/clerical & 10.2 & 0.6 & 0.6 & 11.3 & 116 \\
\hline $\begin{array}{l}\text { Agricultural/self- } \\
\text { employed }\end{array}$ & 9.7 & 0.7 & 1.8 & 12.3 & 1,037 \\
\hline Sales & 7.6 & 1.7 & 2.5 & 11.8 & 140 \\
\hline Manual labor & 6.1 & 1.5 & 1.2 & 8.8 & 297 \\
\hline Other & 13.2 & 0.7 & 2.1 & 16.0 & 197 \\
\hline None & 11.6 & 0.0 & 0.0 & 11.6 & 17 \\
\hline \multicolumn{6}{|l|}{ Age Group } \\
\hline $15-24$ & 2.9 & 0.9 & 0.6 & 4.4 & 408 \\
\hline $25-34$ & 7.8 & 0.7 & 1.2 & 9.7 & 657 \\
\hline $35-44$ & 13.2 & 1.4 & 2.1 & 16.7 & 489 \\
\hline $45-54$ & 16.9 & 0.2 & 4.1 & 21.3 & 251 \\
\hline All & 9.4 & 0.9 & 1.7 & 12.0 & 1,804 \\
\hline
\end{tabular}

Intoxication before sex and negative outcomes
There is an association between intoxication before last sexual intercourse and having had sexual intercourse with a non-regular partner and non-use of condoms. Among men, those who were intoxicated 
before last sexual intercourse were more likely to have had sex with non-regular partners $(\mathrm{OR}=\mathrm{I} .78$, 95\% CI: I.04-3.03) compared to those who were not intoxicated. Similarly, men who reported that their partners were intoxicated before last sexual intercourse were more likely to have had sex with nonregular sexual partners $(\mathrm{OR}=3.06$, 95\% CI: I.396.72). Men who were intoxicated before last sexual intercourse were more likely to have had unpro- tected sex (OR = I.7I, 95\% CI: I.07-2.73) but those whose partners were intoxicated were less likely to have had unprotected sex $(\mathrm{OR}=0.42,95 \% \mathrm{CI}$ : 0.20-0.87) (Table 3). Therefore, intoxication of men is associated with having sex with non-regular sexual partners and non-use of condoms, but when their partners are intoxicated men are more likely to use condoms.

Table 2

Weighted prevalence of reported intoxication during previous sexual activity by background characteristics of women

\begin{tabular}{|c|c|c|c|c|c|}
\hline $\begin{array}{l}25-34 \\
\text { Characteristics } \\
35-44 \\
45-49 \\
\text { All }\end{array}$ & $\begin{array}{c}0.6 \\
\text { Respondent } \\
\text { alone } \\
\text { intoxiçated }\end{array}$ & $\begin{array}{c}15.2 \\
\text { Partner alone } \\
\text { intoxicated } \\
16.4 \\
13.5)\end{array}$ & $\begin{array}{c}2.2 \\
\text { Both } \\
3.8 \\
\text { intoxicated } \\
\left(\frac{1}{2.2}\right)\end{array}$ & $\begin{array}{c}18.0 \\
\text { Any } \\
22.5 \\
\text { intoxicated } \\
20.6 \\
16.20)\end{array}$ & $\begin{array}{c}2,376 \\
\text { Total } \\
1,353 \\
\text { respondents } \\
\text { 3. } \\
6,2)_{3}\end{array}$ \\
\hline & $(\%)$ & & & & \\
\hline \multicolumn{6}{|l|}{ Region } \\
\hline Central & 0.3 & 9.5 & 0.8 & 10.6 & 1,237 \\
\hline Kampala & 0.5 & 7.0 & 1.9 & 9.4 & 490 \\
\hline Eastern & 0.6 & 14.1 & 2.3 & 17.0 & 1,520 \\
\hline Northern & 0.7 & 19.9 & 5.5 & 26.1 & 1,291 \\
\hline Western & 0.5 & 12.8 & 0.9 & 14.1 & 1,714 \\
\hline \multicolumn{6}{|l|}{ Education } \\
\hline None & 0.4 & 18.0 & 6.1 & 24.4 & 1,329 \\
\hline Primary & 0.6 & 14.0 & 1.2 & 15.8 & 3,729 \\
\hline Secondary & 0.5 & 6.9 & 1.2 & 8.6 & 934 \\
\hline Higher & 0.5 & 7.0 & 0.5 & 8.0 & 260 \\
\hline \multicolumn{6}{|l|}{ Marital Status } \\
\hline Single & 0.6 & 4.9 & 1.2 & 6.6 & 528 \\
\hline Married & 0.5 & 14.0 & 2.2 & 16.7 & 5,129 \\
\hline Widowed/separated & 0.6 & 16.8 & 3.6 & 21.0 & 595 \\
\hline \multicolumn{6}{|l|}{ Residence } \\
\hline Urban & 0.6 & 8.2 & 2.8 & 6.6 & 998 \\
\hline Rural & 0.5 & 14.5 & 2.1 & 16.7 & 5,254 \\
\hline \multicolumn{6}{|l|}{ Religion } \\
\hline Catholic & 0.5 & 16.2 & 3.6 & 20.4 & 2,699 \\
\hline Protestant & 0.8 & 14.7 & 1.7 & 17.1 & 2,131 \\
\hline Muslim & 0.1 & 4.1 & 0.4 & 4.7 & 728 \\
\hline Other & 0.2 & 8.9 & 0.5 & 9.6 & 694 \\
\hline \multicolumn{6}{|l|}{ Occupation } \\
\hline Professional/clerical & 0.3 & 7.8 & 8.7 & 8.4 & 232 \\
\hline $\begin{array}{l}\text { Agricultural/self- } \\
\text { employed }\end{array}$ & 0.6 & 14.4 & 7.7 & 17.5 & 4,104 \\
\hline Sales & 0.5 & 10.1 & 8.2 & 12.6 & 549 \\
\hline Manual labor & 0.0 & 17.7 & 9.7 & 20.6 & 327 \\
\hline Other & 0.5 & 14.4 & 7.3 & 17.7 & 454 \\
\hline None & 0.2 & 9.2 & 5.2 & 10.0 & 587 \\
\hline \multicolumn{6}{|l|}{ Age Group } \\
\hline $15-24$ & 0.5 & 8.0 & 0.9 & 9.5 & 2,126 \\
\hline
\end{tabular}


Table 3

Multivariate logistic regression: Reported intoxication before last sexual intercourse and its association with risky sexual behavior among men

\begin{tabular}{|c|c|c|c|c|}
\hline \multirow[b]{2}{*}{ Factors } & \multicolumn{2}{|c|}{$\begin{array}{c}\text { Had sexual intercourse with } \\
\text { non-regular partner }\end{array}$} & \multicolumn{2}{|c|}{$\begin{array}{c}\text { Condom use before last } \\
\text { sexual intercourse }\end{array}$} \\
\hline & $\begin{array}{l}\text { Model I with } \\
\text { respondent } \\
\text { intoxicated }\end{array}$ & $\begin{array}{l}\text { Model II with part- } \\
\text { ner } \\
\text { intoxicated }\end{array}$ & $\begin{array}{l}\text { Model I with } \\
\text { respondent } \\
\text { intoxicated }\end{array}$ & $\begin{array}{l}\text { Model II with } \\
\text { partner } \\
\text { intoxicated }\end{array}$ \\
\hline \multicolumn{5}{|l|}{ Bivariate } \\
\hline $\begin{array}{l}\text { Respondent intoxicated } \\
\text { (base }=\text { not intoxicated) }\end{array}$ & $\begin{array}{c}0.96 \\
(0.60-1.56)\end{array}$ & & $\begin{array}{c}1.92 \\
(1.22-3.01)^{* * * *}\end{array}$ & \\
\hline $\begin{array}{l}\text { Partner intoxicated } \\
\text { (base = not intoxicated) }\end{array}$ & & $\begin{array}{c}2.19 \\
(1.11-4.29) *\end{array}$ & & $\begin{array}{c}0.81 \\
(0.43-1.55)\end{array}$ \\
\hline $\begin{array}{l}\text { Multivariate } \\
\text { Respondent intoxicated } \\
\text { (base = not intoxicated) }\end{array}$ & $\begin{array}{c}1.78 \\
(1.04-3.03)^{*}\end{array}$ & & $\begin{array}{c}1.71 \\
(1.07-2.73)^{*}\end{array}$ & \\
\hline $\begin{array}{l}\text { Partner intoxicated } \\
\text { (base = not intoxicated) }\end{array}$ & & $\begin{array}{c}3.06 \\
(1.39-6.72)^{* * *}\end{array}$ & & $\begin{array}{c}0.42 \\
(0.20-0.87)^{*}\end{array}$ \\
\hline Region & + & + & + & \\
\hline Education & & + & & + \\
\hline \multicolumn{5}{|l|}{ Marital status } \\
\hline Residence & + & + & + & \\
\hline Religion & & + & + & + \\
\hline Occupation & + & + & + & + \\
\hline Age group & + & + & & + \\
\hline Goodnesss of fit: Lemeshow & $\chi^{2}=12.3$ & $\chi^{2}=12.4$ & $\chi^{2}=8.2$ & $\chi^{2}=4.22$ \\
\hline chi-sq \& p-value & $\mathrm{p}=.14$ & $\mathrm{p}=.14$ & $\mathrm{p}=.42$ & $\mathrm{p}=.84$ \\
\hline
\end{tabular}

+ factors included in the final model

$* \mathrm{p}<.05 ; * * \mathrm{p}<.01 ; * * * \mathrm{p}<.001$

Among women, those who were intoxicated before last sexual intercourse were less likely to have had non-regular partners compared to those who were not intoxicated $(\mathrm{OR}=0.55$, 95\% CI: $0.32-$ 0.95). Similarly, women who reported that their partners were intoxicated before last sexual intercourse were less likely to have had non-regular partners $(\mathrm{OR}=0.76,95 \% \mathrm{CI}: 0.60-0.96) \mathrm{com}$ pared to those who reported that their partners were not intoxicated before last sexual intercourse. On condom use, women who reported that they or their partners were intoxicated before last sexual intercourse were more likely to have had unprotected sex compared to those who did not report intoxication, but this difference was statistically significant only when the partner was intoxicated (OR $=1.55,95 \%$ CI: I.I2-2.I5) (Table 4). Therefore intoxication of women before last sexual intercourse was associated with having had sex with regular sexual partner, while reported intoxication of their partners was associated with having had unprotected sex. 


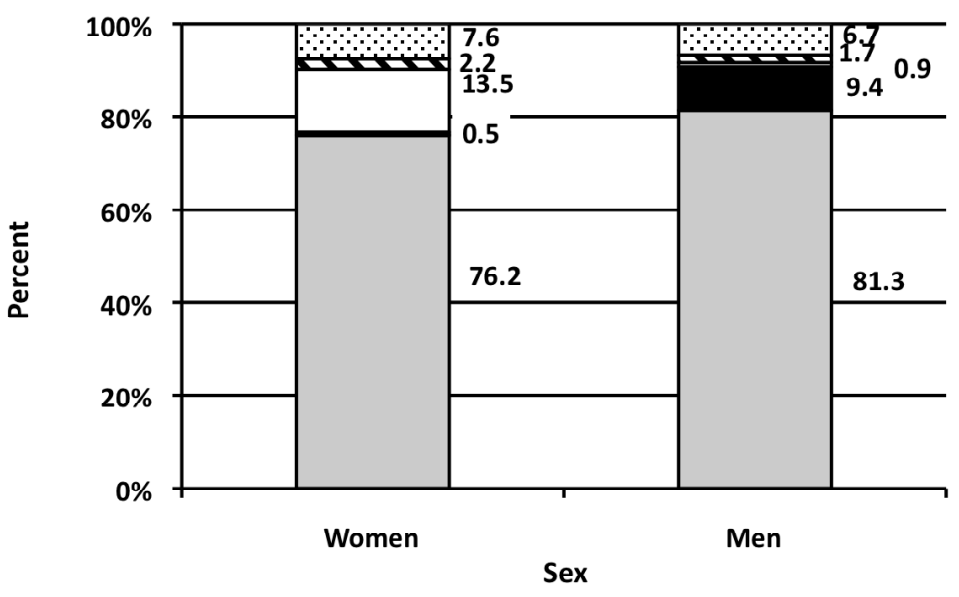

Figure 1: Reported alcohol consumption before last sexual intercourse
Wneither drunk but consumed alcohol Dboth drunk

Dpartner drunk only

respondent drunk only

口none drank alcohol

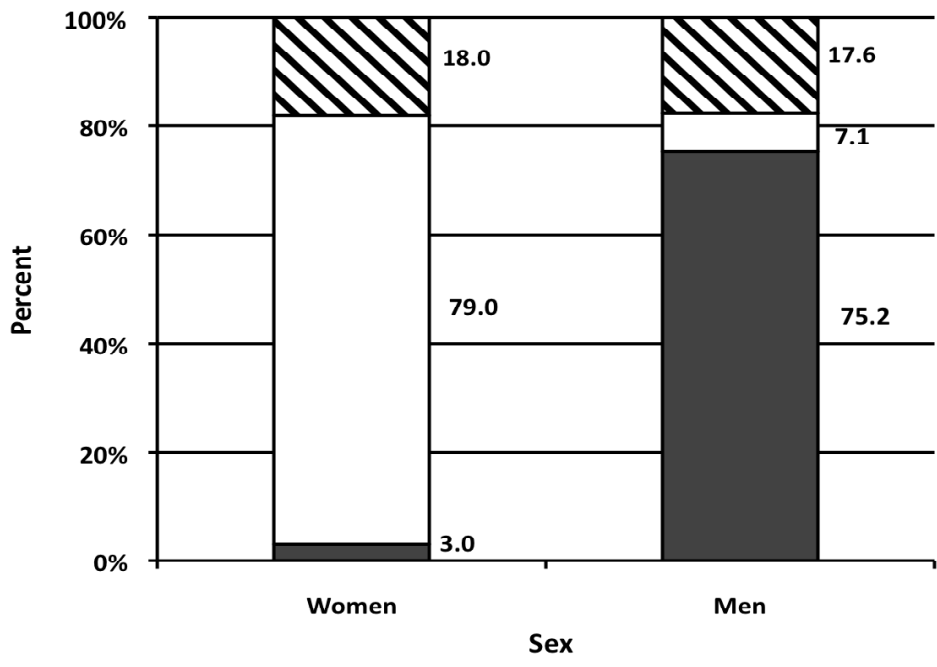

Figure 2: Pattern of intoxication before last sexual intercourse

\section{Nboth drunk \\ $\square$ partner drunk only \\ $\square$ respondent drunk only}


Table 4

Multivariate logistic regression: Intoxication before last sexual intercourse and its association with risky sexual behavior among women

\begin{tabular}{|c|c|c|c|c|}
\hline \multirow[b]{2}{*}{ Factors } & \multicolumn{2}{|c|}{$\begin{array}{c}\text { Had sexual intercourse with } \\
\text { non-regular partner }\end{array}$} & \multicolumn{2}{|c|}{$\begin{array}{l}\text { Condom use before last } \\
\text { sexual intercourse }\end{array}$} \\
\hline & $\begin{array}{l}\text { Model I with } \\
\text { respondent } \\
\text { intoxicated }\end{array}$ & $\begin{array}{l}\text { Model II with part- } \\
\text { ner } \\
\text { intoxicated }\end{array}$ & $\begin{array}{l}\text { Model I with } \\
\text { respondent } \\
\text { intoxicated }\end{array}$ & $\begin{array}{l}\text { Model II with } \\
\text { partner } \\
\text { intoxicated }\end{array}$ \\
\hline \multicolumn{5}{|l|}{ Bivariate } \\
\hline $\begin{array}{l}\text { Respondent intoxicated } \\
\text { (base }=\text { not intoxicated) }\end{array}$ & $\begin{array}{c}0.96 \\
(0.60-1.56)\end{array}$ & & $\begin{array}{c}1.92 \\
(1.22-3.01)^{* * *}\end{array}$ & \\
\hline $\begin{array}{l}\text { Partner intoxicated } \\
\text { (base }=\text { not intoxicated) }\end{array}$ & & $\begin{array}{c}2.19 \\
(1.11-4.29)^{*}\end{array}$ & & $\begin{array}{c}0.81 \\
(0.43-1.55)\end{array}$ \\
\hline \multicolumn{5}{|l|}{ Multivariate } \\
\hline $\begin{array}{l}\text { Respondent intoxicated } \\
\text { (base }=\text { not intoxicated) }\end{array}$ & $\begin{array}{c}1.78 \\
(1.04-3.03)^{*}\end{array}$ & & $\begin{array}{c}1.71 \\
(1.07-2.73)^{* *}\end{array}$ & \\
\hline $\begin{array}{l}\text { Partner intoxicated } \\
\text { (base = not intoxicated) }\end{array}$ & & $\begin{array}{c}3.06 \\
(1.39-6.72)^{* * *}\end{array}$ & & $\begin{array}{c}0.42 \\
(0.20-0.87)^{*}\end{array}$ \\
\hline Region & + & + & + & \\
\hline $\begin{array}{l}\text { Education } \\
\text { Marital status }\end{array}$ & & + & & + \\
\hline Residence & + & + & + & \\
\hline Religion & & + & + & + \\
\hline Occupation & + & + & + & + \\
\hline Age group & + & + & & + \\
\hline Goodnesss of fit: Lemeshow & $\chi^{2}=12.3$ & $\chi^{2}=12.4$ & $\chi^{2}=8.2$ & $\chi^{2}=4.22$ \\
\hline chi-sq \& p-value & $\mathrm{p}=.14$ & $\mathrm{p}=.14$ & $\mathrm{p}=.42$ & $\mathrm{p}=.84$ \\
\hline
\end{tabular}

+ factors included in the final model

$* \mathrm{p}<.05 ; * * \mathrm{p}<.01 ; * * * \mathrm{p}<.001$

\section{Discussion}

These data show a high prevalence of alcohol use and intoxication before last sexual intercourse in Uganda. The data have further shown that intoxication before sex is associated with the HIV risk behaviors of having sex with a non-regular sexual partner and non-use of a condom. Thus given the country's HIV prevalence, estimated at $6.4 \%$ (Uganda Ministry of Health \& ORC Macro, 2006), there is cause for concern over the high level of intoxication before sex.

The high level of both alcohol use and intoxication shows that many people could have reported sufficiently high quantities of alcohol intake in association with sexual behavior as to lead to intoxication. Indeed, one may speculate that for many, their drinking may have been pursued in order to get intoxicated.
High prevalence of alcohol use before sex has also been reported by another study that was conducted in Rakai district in southwestern Uganda (Zablotska et al., 2006), and other regions (Tuvalu Central Statistics Division \& Macro International Inc., 2007). Elsewhere, a study in Mexico reported high levels of alcohol before sex (23\%) among HIVseropositive male clients of sex workers (Patterson et al., 2009). Higher levels of intoxication (50\%) have been reported among clients of sex workers in Zimbabwe (Tuvalu Central Statistics Division \& Macro International Inc., 2007).

The demographic patterns of intoxication before sex that we found were quite similar to the patterns of general alcohol consumption found in a Ugandan population study in 2003 (Tumwesigye \& Kasirye, 2006). As in the 2003 survey, the prevalence of frequent or heavy alcohol consumption was highest in the northern region, and among uneducated people, older people, unemployed people, 
Catholics and rural residents. The northern part of Uganda experienced more than a decade of war and internal displacement of the population around the time of both studies, and so higher levels of intoxication in the northern region could be attributed to the this social instability. In the case of older people, this population is more likely to be able to afford to purchase alcohol and hence more likely to get intoxicated.

The finding that men were more likely to be intoxicated before sex than women is not surprising and agrees with many research findings. Men are more likely than women to drink before sex and and even more likely than women to be intoxicated before sex (Tumwesigye, Kasirye, \& Nansubuga, 2009). They are also more likely to drink alcohol frequently and in larger amounts than women (Tumwesigye et al., 2009). A new study of women across Africa has confirmed a long-held view that female drinking is not very common, and attributes this to gender roles, religion and cultural tradition (Martinez, Røislien, Naidoo, \& Clausen, 20II). Alcohol consumption by men is more accepted culturally (Woolf-King \& Maisto, 20II). Furthermore, it is men who are more likely to have the economic means to buy alcohol. The association between intoxication and risky sexual behavior concurs with many other findings, such as those carried out by Clark and colleagues in the U.S.A. (Clark et al., I997), Castilla and colleagues (Castilla et al., I999) in Spain and Sunmola and colleagues in Nigeria (Sunmola et al., 2007). Non-significance of association between intoxication of women and unprotected sex but significant relationship between intoxication of women's sexual partners and reported unprotected sex are in agreement with findings by Kalichman and colleagues (Kalichman, Simbayi, Jooste, et al., 2007, Russell et al., 2007).

Gender differences in the association of intoxication with risky sexual behavior are evident in this study. Intoxication of the male respondents was associated with having sex with non-regular sexual partners and non-use of condoms, while intoxication of the female respondents was associated with having sex with regular sexual partners and it did not have a significant association with condom use. Women whose partners were intoxicated before last sexual intercourse were less likely to report condom use, while men whose partners were intoxicated were more likely to report condom use. This is consistent with other findings. A study in South Africa found that the odds for engaging in unprotected sex were highest when the male partner had been drinking (Kiene et al., 2008).

\section{Conclusions and policy implications}

The prevalence of intoxication before last sexual intercourse is relatively high, especially among men. There is a strong association observed between intoxication before last sexual intercourse and unprotected sex and sex with non-regular partners. Women are disproportionately affected. When their partners are intoxicated condoms are less likely to be used but when they are intoxicated their male partners are more likely to use condoms.

The implication that seems clear from these results is that interventions that aim to reduce HIV risk behavior should include measures to reduce intoxication. More effort is also needed to protect women from having unprotected sex with intoxicated partners. Furthermore, family planning efforts, STD/STI prevention and HIV counselling and testing programs should integrally address alcohol use and heavy consumption and these behaviors in association with sexual intercourse. Our results emphasize that efforts to reduce alcohol intake and especially intoxication in association with sex should be central to these programs' strategies.

\section{Study limitations}

The survey was cross-sectional and it is impossible to definitively identify a causal relationship in the associations observed. One cannot with certainty determine whether it is alcohol consumption in association with sexual encounters that caused the risky behavior or, rather, that individuals with multiple risk tendencies also tend to consume alcohol more often, and specifically more often in association with sexual activity. These associations are thus best conceived of as interplay.

It is quite hard for some individuals to tell the difference between getting intoxicated and just having consumed alcohol. Answers to the question whether one was intoxicated or had just consumed alcohol are subjective and likely to be both attitudinally and socially determined (Kerr, Greenfield, \& Midanik, 2006). What some people see as having drunk alcohol others see as having become intoxicated, and vice versa. A more objective measure or quantification of alcohol consumption would have been useful. Nonetheless, these data still provide some good insights into the magnitude of, and the 
relationship between, alcohol consumption and HIV risk behavior.

\section{References}

Aicken, C. H., Nardone, A., \& Mercer, C. H. (20I0). Alcohol misuse, sexual risk behaviour and adverse sexual health outcomes: Evidence from Britain's national probability sexual behaviour surveys. Journal of Public Health, 33, 262-272.

Bisakha, S. (2002). Does alcohol-use increase the risk of sexual intercourse among adolescents? Evidence from the NLSY97. Journal of Health Economics, 21, 1085-1093.

Bryant, K. J. (2006). Expanding research on the role of alcohol consumption and related risks in the prevention and treatment of HIV/AIDS. Substance Use Q Misuse, 41, I465-1507.

Castilla, J., Barrio, G., Belza, M. J., \& Fuente, L. L. (I999). Drug and alcohol consumption and sexual risk behaviour among young adults: Results from a national survey. Drug and Alcohol Dependence, 56, 47-53.

Clark, C. L., Kissinger, P., Bedimo, A. L., Dunn, P., \& Albertin, H. (1997). Determination of factors associated with condom use among women infected with human immunodeficiency virus. International Journal of STD Q AIDS, 8, 229-233.

Cook, R. L., \& Clark, D. (2005). Is there an association between alcohol consumption and sexually transmitted diseases? A systematic review. Sexually Transmitted Diseases, 32, I55-164.

Cooper, L. (2002). Alcohol use and risky sexual behavior among college students and youth: Evaluating the evidence. Journal of Studies on Alcohol, 14(Suppl), IOI-II7.

Erdural, S. (2006). A method for robust design of products or processes with categorical response. (Doctoral dissertation). Retrieved from www.belgeler.com/blg/ys2/a-method-forrobust-design-of-products-or-processes-withcategorical-response-kategorik-ciktisi-olanurun-veya-sureclerin-robust-tasarimi-icin-birmetot.

Gerbi, G. B., Habtermariam, T., Tameru, B., \& Nganwa, D. (2009). The correlation between alcohol consumption and risky sexual behaviors among people living with HIV/AIDS. Journal of Substance Abuse, 14, 90-100.

Greenfield, T. K., Nayak, M. B., Bond, J., Patel, V.,
Trocki, K., \& Pillai, A. (20I0). Validating alcohol use measures among male drinkers in Goa: Implications for research on alcohol, sexual risk, and HIV in India. AIDS and Behavior, 14, 84-93.

Hosmer, D. W., \& Lemeshow, S. (I989). Applied logistic regression. New York, U.S.A.: John Wiley and Sons.

Kalichman, S. C., Simbayi, L. C., Cain, D., \& Jooste, S. (2007). Alcohol expectancies and risky drinking among men and women at highrisk for HIV infection in Cape Town South Africa. Addictive Behaviors, 32, 2304-2310.

Kalichman, S. C., Simbayi, L. C., Jooste, S., \& Cain, D. (2007). Frequency, quantity, and contextual use of alcohol among sexually transmitted infection clinic patients in Cape Town, South Africa. American Journal of Drug and Alcohol Abuse, 33, 687-98.

Kalichman, S. C., Simbayi, L. C., Kaufman, M., \& Cain, D. S. (2007). Alcohol use and sexual risks for HIV/AIDS in sub-Saharan Africa: Systematic review of empirical findings. Prevention Science, 8, I4I-I5I.

Kerr, W. C., Greenfield, T. K., \& Midanik, L. T. (2006). How many drinks does it take you to feel drunk? Trends and predictors for subjective drunkenness. Addiction, 101, I428-I437.

Kiene, S. M., Simbayi, L. C., Abrams, A., Cloete, A., Tennen, H., \& Fisher, J. D. (2008). High rates of unprotected sex occurring among HIVpositive individuals in a daily diary study in South Africa: The role of alcohol use. Journal of Acquired Immune Deficiency Syndromes, 42, 219-226.

Kongnyuy, E. J., \& Wiysonge, C. S. (2007). Alcohol use and extramarital sex among men in Cameroon. BMC International Health and Human Rights, 7, 6.

Lavikainen, H. M., Lintonen, T., \& Kosunen, E. (2009). Sexual behavior and drinking style among teenagers: A population-based study in Finland. Health Promotion International, 24, Io8-II9.

Martinez, P., Røislien, J., Naidoo, N., \& Clausen, T. (2OII). Alcohol abstinence and drinking among African women: Data from the world health surveys. BMC Public Health, II, I6o.

Patterson, T. L., Goldenberg, S., Gallardo, M., Lozada, R., Semple S. J., Orozovich P., . . . Strathdee, S. A. (2009). Correlates of HIV, sexually transmitted infections, and associated high-risk 
behaviors among male clients of female sex workers in Tijuana, Mexico. AIDS, 23, I765I77I.

Russell, T., Do, A. N., Setik, E., Sullivan, P. S., Rayle V. D., Fridlund C. A., ... Fleming, P. L. (2007). Sexual risk behaviors for HIV/AIDS in Chuuk State, Micronesia: The case for HIV prevention in vulnerable remote populations. PLoS One, 2.

Sunmola, A., Olley, B., \& Oso, G. E. (2007). Predictors of condom use among sexually active persons involved in compulsory national service in Ibadan, Nigeria. Health Education Research, 22, 459-72.

Tumwesigye, N. M., \& Kasirye, R. (2006). Gender and the major consequences of alcohol consumption in Uganda. In I. Obot \& R. Robin (Eds.), Alcohol, gender and drinking problems (pp. I89-208). Geneva, Switzerland: World Health Organization.

Tumwesigye, N. M., Kasirye, R., \& Nansubuga, E. (2009). Is social interaction associated with alcohol consumption in Uganda? Drug and Alcohol Dependence, 103, 9-I5.

Tuvalu Central Statistics Division \& Macro International Inc. (2007). Tuvalu demographic and health survey. Noumea, Uganda: Author.

Uganda Bureau of Statistics \& Macro International Inc. (2007). Uganda demographic and health survey 2006. Calverton, U.S.A.: Uganda Bureau of Statistics and Macro International Inc.

Uganda Ministry of Health \& ORC Macro. (2006). Uganda HIV/AIDS Sero-behavioural Survey 2004-2005. Calverton, U.S.A.: Uganda Ministry of Health and ORC Macro.Weinhardt, L. S., $\&$ Carey, M. P. (2000). Does alcohol lead to sexual risk behavior? Findings from event-level research. Annual Review of Sex Research, 11, I25-I57.

Wilson, D., Sibanda, B., Mboyi, L., Msimanga, S., \& Dube, G. (I990). A pilot study for an HIV prevention programme among commercial sex workers in Bulawayo, Zimbabwe. Social Science Q Medicine, 31, 609-6I8.

Woolf-King, S.E., \& Maisto, S. A. (2OII). Alcohol use and high-risk sexual behavior in subSaharan Africa: A narrative review. Archives of Sexual Behavior, 40, I7-42.

World Health Organization. (2004). Global Status Report on Alcohol 2004. Geneva, Switzerland:
Author.

World Health Organziation. (2010). Global strategy to reduce harmful use of alcohol. Geneva, Switzerland: Author.

World Health Organization. (2011a). Elder abuse and alcohol fact sheet. Geneva, Switzerland: Author.

World Health Organization. (20IIb). Global status report on alcohol and health. Geneva, Switzerland: Author.

Zablotska, I. B., Gray, R. H., Serwadda, D., Nalugoda, F., Kigozi, G., Sewankambo, N.K., . . . Wawer, M. (2006). Alcohol use before sex and HIV acquisition: A longitudinal study in Rakai, Uganda. AIDS, 20(8), II9I-II96. 